\title{
ИСТОРИЧЕСКИЙ ВЗГЛЯД НА РАЗВИТИЕ И СОВРЕМЕННЫЕ ВОЗМОЖНОСТИ КЕРАТОПЛАСТИКИ (ОБЗОР ЛИТЕРАТУРЫ)
}

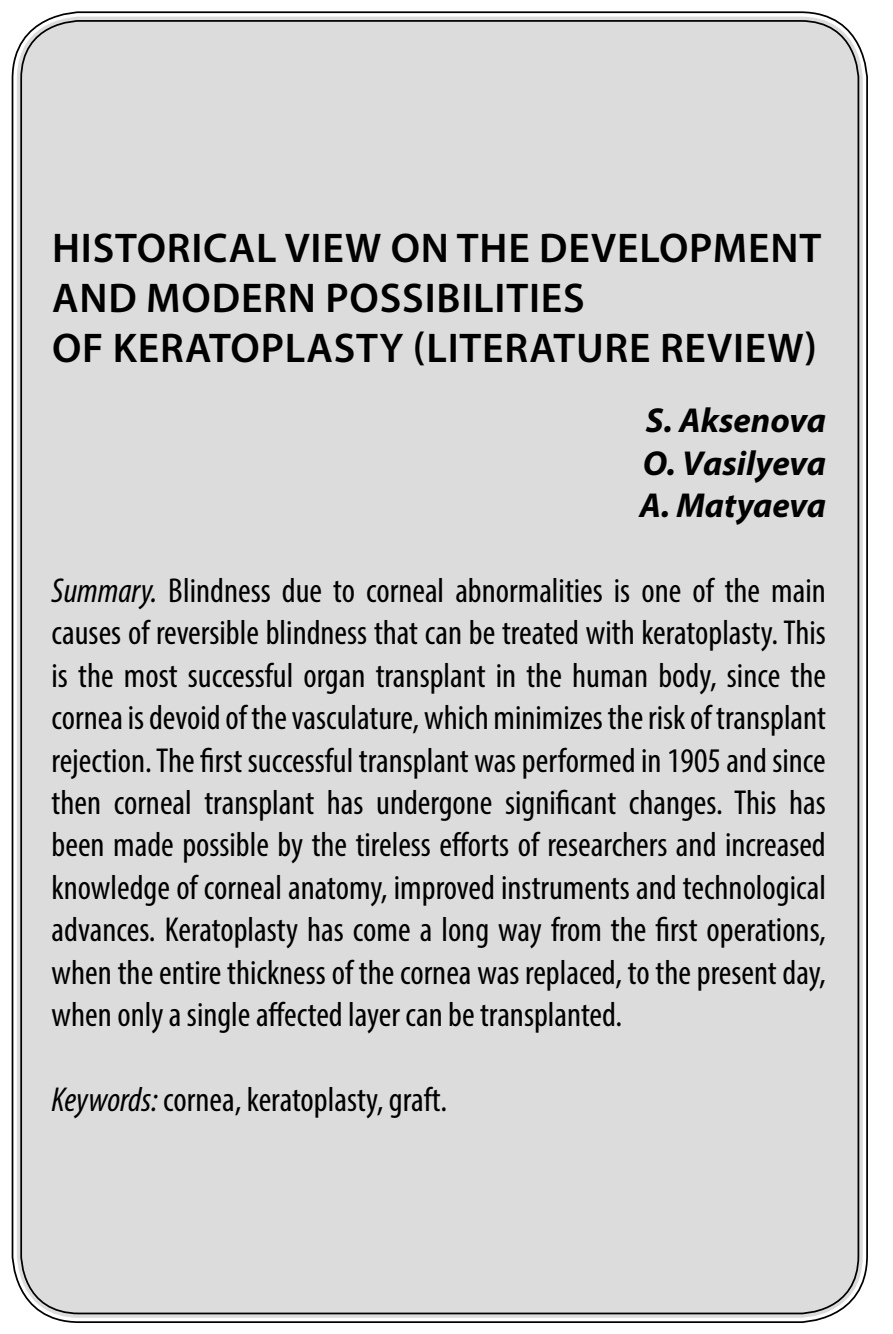

B Российской Федерации велика частота встречаемости офтальмопатологии, а именно - около 11 тысяч человек на 100 тысяч населения страдают заболеваниями глаза. На основании данных Нероева В.В. число слабовидящих и слепых в России составляет 218 тысяч человек, причем, 103 тысячи человек являются абсолютно слепыми. В мировой статистике по причине патологий роговицы слепота стоит на 4-м месте $(5,1 \%)[4]$.

Роговица - довольно уязвимая структурная часть глаза, её прозрачность нарушается вследствие многих воздействующих факторов и заболеваний [3]. Даже интенсивные консервативные методы лечения часто бывают неэффективны, что ведет к образованию бельма различной степени интенсивности и стойкому снижению
Аксенова Светлана Владимировна

Д.м.н., профессор, ФГБОУВО «Начиональный исследовательский Мордовский государственный университет им. Н.П. Огарёва» aksenovamed@mail.ru

Васильева Ольга Александровна К.м.н., дочент, ФГБОУ ВО «Национальный исследовательский Мордовский государственный университет им. Н.П. Огарёва»; Врач-офтальмолог,

ООО «Клиника доктора Куренкова» olga11vasilyeva@gmail.com

Матяева Ангелина Дмитриевна

ФГБОУВО «Начиональный исследовательский Мордовский государственный университет им. Н.П. Огарёва» matyaeva.lina@yandex.ru

Аннотация. Слепота вследствие патологий роговицы — одна из основных причин обратимой слепоты, с которой можно справиться с помощью кератопластики. Это наиболее успешная трансплантация органов в организме человека, поскольку роговица лишена сосудистой сети, что сводит к минимуму риск отторжения трансплантата. Первая успешная трансплантация была проведена в 1905 году, и с тех пор трансплантация роговицы претерпела значительные изменения. Это стало возможным благодаря неустанным усилиям исследователей и увеличению знаний об анатомии роговицы, совершенствованию инструментов и технологическим достижениям. Кератопластика прошла долгий путь со времени первых операций, когда заменялась вся толща роговицы, до наших дней, когда может быть трансплантирован только отдельный пораженный слой.

Ключевые слова: роговица, кератопластика, трансплантат.

зрения. Трансплантация роговицы является практически единственным способом лечения данной патологии $[5,6]$.

Кератопластика представляет собой вид пластической операции, заключающийся в замене патологически изменённой роговицы или её части трансплантатом [2].

Первую успешную операцию сквозной пересадки роговицы при сохранении остроты зрения 0,3 у пациента, потерявшего зрение вследствие ожога обоих глаз, осуществил Эдуард Цирм 7 декабря 1905 года в городе Оломоуц (Чехия) [1].

Развитие кератопластики в России связано с имением академика Владимира Петровича Филатов, кото- 
рый является основателем наиболее известной отечественной офтальмологической школы. Важные заслуги В.П. Филатова: открытие метода сохранения роговицы от трупа человека во влажной камере при температуре $+2-4^{\circ} \mathrm{C}$, разработка новых технологий пересадки роговицы и инструментов, которые позволили выполнить данные операции. Владимир Петрович первым предложил для фиксации трансплантата, укрывать его участком слизистой оболочки склеры, выкроенной в верхнем отделе глазного яблока в форме ленты [60, 61].

Позже, В.П.Филатов совместно с конструктором А.П. Марциновским разработали ряд трепанов. ФМ-1, ФМ-3, ФМ-4 получили наиболее широкое распространение.

Кроме того, В.П. Филатовым, при помощи Д.Г. Бушмича, разработана классификация помутнений роговиц, отражающая степень их пригодности для пересадки, и включает 5 категорий.

Заслуги академика В.П. Филатова не только оказали огромное влияние на развитие кератопластики во всем мире, но и позволили отечественной офтальмологии занять передовые рубежи по пересадке роговицы $[62,63]$.

Существуют различные анатомические и клинические параметры, которые необходимо оценить перед планированием типа трансплантации роговицы. В настоящее время существует несколько целей трансплантации роговицы: оптическая (восстановление или улучшение зрения), лечебная (обратное развитие или прекращение патологического процесса в роговице), косметическая (косметический эффект без улучшения зрения), тектоническая (восстановление целостности роговицы), мелиоративная (перед оптическими операциями для «укрепления» роговицы) [5, 7].

Существуют следующие виды кератопластики: сквозная и послойная. Методика сквозной кератопластики применяется лишь в тех случаях, когда имеются грубые необратимые изменения стромы. Эта техника одна из наиболее травматичных, к тому же сопровождается высоким риском развития тяжелых осложнений. Поэтому, в настоящее время идет активное развитие методик послойных операций, позволяющих минимизировать операционные риски и создавать условия сохранения прозрачности роговицы. Этот метод выборочной замены пораженной части имеет много преимуществ с точки зрения меньшего количества интраоперационных осложнений, сохранения целостности глазного яблока и меньших шансов отторжения трансплантата в послеоперационном периоде, поскольку трансплантируется меньшее количество ткани по сравнению со сквозной кератопластикой [10-12]. Таким образом, трансплантация роговицы в широком смысле классифицируется как сквозная (PK), передняя и задняя послойная кератопластика. Передняя послойная кератопластика подразделяется на SALK (Superficial Anterior Lamellar Keratoplasty - Передняя послойная кератопластика), DALK (Deep Anterior Lamellar Keratoplasty - Глубокая передняя послойная кератопластика). Заднюю кератопластику подразделяют на DSAEK (Descemet Stripping Automated Endotelial Keratoplasty - Задняя автоматизированная послойная кератопластика) и DMEK (Descemet Membrane Endotelial Keratoplasty - Эндотелиальная кератопластика десцеметовой оболочки) [13-15]. Классификация в зависимости от размера заменяемого участка роговицы следующая: частичная кератопластика (4,5-6,0 мм в диаметре), субтотальная кератопластика (6,5-9,0 мм в диаметре), тотальная кератопластика (9,512,0 мм в диаметре) [8].

Послойная (передняя и задняя) кератопластика подразумевает хирургическую замену только пораженной ткани роговицы при сохранении здоровой ткани роговицы хозяина. Селективная кератопластика предлагает несколько преимуществ по сравнению с проникающей кератопластикой, например, более низкая вероятность отторжения трансплантата, меньшая потеря эндотелиальных клеток, более быстрая зрительная адаптация. Эти новые хирургические процедуры быстро становятся предпочтительным вариантом терапии специфических дисфункций роговицы, затрагивающих эпителий и строму (SALK, DALK) или эндотелий роговицы (DSAEK, DMEK). В течение последнего десятилетия непрерывное совершенствование хирургических методов и разработка инновационных инструментов значительно улучшили методику трансплантации роговицы. Послойная кератопластика облегчает операцию на роговице, обеспечивает превосходные результаты и может успешно восстановить зрение при слепоте, связанной с патологией роговицы [16].

Передняя послойная кератопластика может выполняться практически во всех случаях помутнения роговицы, при наличии интактного эндотелия [17].

Передняя послойная кератопластика (SALK) впервые была описана Кауфманом и др. в 2003 году. Она используется для лечения помутнений роговицы, затрагивающих передние 30-40\% роговицы. Основными показаниями являются поверхностные рубцы, возникшие в результате заживления кератита, трахома, травмы, поверхностные дистрофии или дегенерации роговицы $[18,19]$.

DALK показана при более глубоких поражениях роговицы, чем SALK и применяется при наличии помутнения в средних слоях роговицы, решетчатой и пятнистой дис- 
трофии роговицы, рецидивирующем птеригиуме, дермоиде, неоплазме [22].

С развитием науки в области передней послойной кератопластики появилось много техник проведения данных операций: прямая открытая диссекция, описанная Anwar в 1974 году [28]; диссекция с интрастромальной инъекцией воздуха по Archila и Deep (1985 г.) [23]; pacсечение гидроделаминированием, изобретенное Sugita и Kondo [24, 25]; закрытая диссекция (1999 г.) и рассечение роговицы с использованием вискоэластиков (2000 г.) по Melles и др. [26, 27]; диссекция с использованием техники «big bubble», открытая Anwar и Teichmann (2002 г.) $[20,21]$; кератопластика с использованием микрокератома LASIK (Laser-Assisted in Situ Keratomileusis) [29-31]; послойная кератопластика с использованием фемтосекундного лазера $[32,33]$.

Задняя послойная кератопластика используется для замены глубоких слоев роговицы и лечения состояний, при которых поражен только эндотелий, а остальная часть роговицы здорова. Следовательно, показаниями для задней послойной кератопластики являются: эндотелиальная дистрофия роговицы Фукса, задняя полиморфная дистрофия роговицы, наследственная врожденная эндотелиальная дистрофия роговицы, иридокорнеальный эндотелиальный синдром, вирусная эндотелиальная дисфункция, афакичная и псевдофакичная буллезная кератопатия $[35,36]$.

Положительные стороны задней послойной кератопластики заключаются в применении современных микроинвазивных технологий, позволяющих создать тонкий срез донорской роговицы и свести к минимуму возможность развития серьезных осложнений. Кроме того, при данных технологиях гораздо реже возникает отторжение трансплантата, создаются более благоприятные условия для приживления донорского материала.

Описания метода задней послойной кератопластики появились в 1956 г. Первым трансплантацию эндотелия и задних слоев стромы роговицы осуществил C.W. Tillet [37]. В ходе операции был выполнен лимбальный разрез длиной 12 мм, через который проводилось расслаивание роговицы. Затем, задние слои были отсечены ножницами. В образованное ложе был уложен трансплантат и зафиксирован швами. Швы накладывались и в области лимба.

J.I. Barraquer в 1972 г. разработал новый способ задней кератопластики [38]. Операция проводилась по методике «открытого неба». Первый этап - создание кератомом поверхностного лоскута роговицы на ножке. Второй этап - трепанация задних слоев роговицы и помещение в образованное ложе трансплантата. Затем проводилась фиксация швами донорского материала и поверхностного роговичного лоскута. Данная методика имеет ряд недостатков, в частности наличие вертикального рубца всех слоев роговицы [39-43].

B 1998 г. G.R. Melles модернизировал операцию C.W. Tillet [44]. Лимбальный разрез он сократил до длины 9 мм. Следующий этап - расслаивание роговицы на глубине 2/3 толщины стромы, когда в сформированный карман помещался специализированный трепан, с помощью которого выкраивались задние слои роговицы. Затем вводился трансплантат и расправлялся путем введения воздуха в переднюю камеру глаза. При данной операции швы накладывались только на лимбальный разрез, трансплантат фиксировался благодаря насосной функции эндотелия, выпоту фибрина и стромальной регенерации $[45,46]$. Позднее, G.R. Melles усовершенствовал методику путем сложения трансплантата в дупликатуру, что позволило сократить лимбальный разрез до 5 мм [47]. В 2004 г. тем же автором была предложена техника выполнения десцеметорексиса с целью сохранения стромы при повреждениях только десцеметовой мембраны и эндотелия [48]. Полноценная строма сохраняет трофику и иннервацию роговицы, что способствует благоприятному и быстрому восстановлению после операции, а также обеспечивает более высокие зрительные функции.

Новый способ трансплантации при помощи микрокератома был предложен в 2006 г. M. Gorovoy. Данная методика была названа DSAEK (Descemet's stripping automated endothelial keratoplasty), она позволяет создать ультратонкий трансплантат, тем самым снижая вероятность возникновения неблагоприятных последствий [49]. В России первая операция DSAEK была проведена в 2013 г. Б.Э. Малюгиным [50].

В 2008 г. M. Bursin разработал глайд (Bursinglide), который позволил имплантировать трансплантат через разрез 4 мм. В инструмент воронковидной формы укладывается трансплантат эндотелием кверху, затем устройство переворачивается и кончик его вводится в переднюю камеру глаза. С противоположной стороны производится парацентез, через него вводится микропинцет, который вытягивает трансплантат из глайда [51].

B 2006 г. G.R. Melles предложил технику изолированной трансплантации десцеметовой мембраны, названной DMEK (Descemet's membrane endothelial keratoplasty) $[52,53]$. В России данный вид операции был проведен впервые в 2008 г. в НИИ им. Гельмгольца г. Москва [54].

В связи с проблемой неравномерности толщины трансплантата B. Seitz с соавт. в 2003 г. предложил методику фемтолазерной диссекции стромы роговицы 
[55]. Впервые данная техника была выполнена в 2007 г. Y.Y. Cheng, он провел заднюю послойную кератопластику с выкраиванием донорского трансплантата с помощью фемтосекундного лазера (FS-DSEK) [56].

Последней инновацией в ламеллярной хирургии является PDEK (pre-Descemet's endothelial keratoplasty). Новая техника возникла в связи с открытием в 2013 году в структуре роговицы слоя Дуа, находящегося между стромой и десцеметовой мембраной $[57,58]$. В феврале 2017 г. Dua с соавт. представили инструмент для проведения пневмодиссекции роговицы в условиях операции PDEK [59].

За последние несколько лет наука совершила большой шаг в исследовании проблем кератопластики и соз- дании новых способов пересадки роговицы. Послойная трансплантация дает большие преимущества и устраняет основные риски, связанные со сквозной кератопластикой. Но и ламеллярная кератопластика имеет ряд неблагоприятных нюансов. В связи с чем, необходимо дальнейшее изучение проблемы.

Таким образом, в связи с постоянно увеличивающимся количеством пациентов, которым необходимо хирургическое вмешательстве в виде кератопластики, которая становится в большинстве случаев единственной возможностью возвращения пациенту нормального зрения, поднимается вопрос о постоянном усовершенствовании технологий оперативного лечения, разработке новых методов с использованием нано- и биотехнологий.

\section{ЛИТЕРАТУРА}

1. Zirm E.K. Eine erfolgreiche totale Keratoplastik (A successful total keratoplasty).1906. Refract Corneal Surg. 1989; 5:258-61.

2. Аветисов С.Э., Офтальмология. Национальное руководство / под ред. Аветисова С.Э., Егорова Е.А., Мошетовой Л.К., Нероева В.В., Тахчиди Х.П.- М.: ГЭОТАР-Медиа, 2019. - 752.

3. Ж Жабоедов Г.Д. Офтальмология / Г.Д. Жабоедов, Р.Л. Скрипник, Т.В. Баран.— К.: ВСИ «Медицина», 2011. — 448 с.

4. Vajpayee R.B. [et al.] One donor cornea for 3 recipients: a new concept for corneal transplantation surgery // Arch. Ophthalmol.— 2007.— Vol. 125, № 4.— P. 552-554.

5. Копаева В.Г. Глазные болезни. Основы офтальмологии: Учебник — М.: Медицина, 2012. — 560 c.

6. Данилова Д.И. Оптическая кератопластика. Бюллетень медицинских интернет-конференций -2016. Т. 6. № 5. — С. 78.

7. Кристофер Дж. Рапано. Роговица.— М.: ГЭОТАР-Медиа, 2010.- 320 с.

8. Бирич Т.А. Офтальмология. Учебник для студентов медицинских вузов. — Минск: Выш. шк., 2007. — 555 с.

9. Gain P., Jullienne R., He Z., Aldossary M., Acquart S., Cognasse F., et al. Global survey of corneal transplantation and eye banking. JAMA Ophthalmol. 2016;134:16773.

10. Dhanda R.P., Kalevar V. Historical review. International ophthalmic clinics. Boston, MA: Little Brown C0;1972. Corneal surgery; pp. 7-12.

11. Von Hippel A. Eine neue met hode der horn haut transplantation. Arch Ophthalmol. 1888; 34:108-30.

12. Trevor Roper P.D. The history of corneal grafting. London: Butterwork; 1972. pp. 1-5.

13. Rycroft B.W., Romanes G.J. Lamellar corneal grafts clinical report on 62 cases. Br J Ophthalmol. 1952; 36:337-51.

14. Sugar A., Sugar J. Techniques in pen-etrating keratoplasty: a quarter centry of development. Cornea, 2000, vol. 19, no. 5, pp. 603-610.

15. Hjortdal J. Switzerland: Springer; 2015. Corneal Transplantation.

16. George D. Kymionis, Dimitrios G. Mikropoulos, Dimitra M. Portaliou, Kostantinos G. Boboridis, Irini C. Voudouragkaki, Nikolaos D. Dragoumis, Anastasios G.P. Konstas New perspectives on lamellar keratoplasty. Adv. Ther. 2014 May; 31(5):494-511.

17. Soliman A. Al-Kharashi, Majed M. Al-Obailan, Mansour Almohaimeed, Abdullah A. Al-Torbak. Deep anterior lamellar Keratoplasty. Saudi Journal of Ophthalmology (2009) 23, 203-209.

18. Kaufman H.E. The correction of aphakia. XXXVI Edward Jackson memorial lecture. Am J Ophthalmol. 1980; 89:1-10.

19. Kaufman H.E., Insler M.S., Ibrahim-Elzembely H.A, Kaufman S.C. Human fibrin tissue adhesive for sutureless lamellar keratoplasty and scleral patch adhesion: A pilot study. Ophthalmology. 2003; 110:2168-72.

20. Anwar M., Teichmann K.D. Deep lamellar Keratoplasty: surgical techniques for anterior lamellar Keratoplasty with andwithout baring of Descemet's membrane. 2002; 21, 374-383.

21. Anwar M., Teichmann K.D. Big-bubble technique to bare Descemet's membrane in anterior lamellar Keratoplasty. J. Cataract Refract. Surg. 2002; 28, 398-403

22. Marchini G., Mastropasqua L., Pedrotti E., et al. Deep lamellar Keratoplasty by intracorneal dissection. Ophthalmology 2006; 113, $1289-1300$.

23. Archila E.A., Deep L.K. Dissection of host tissue with intrastromal air injection. Cornea 1985; 3, 217-218.

24. Sugita J., Kondo J. Deep lamellar Keratoplasty with complete removal of pathological stroma for vision improvement. Br.J. Ophthalmol. 1997; 81, 184-188.

25. Senoo T., Chiba K., Terada 0., et al. Deep lamellar Keratoplasty by deep parenchyma Detachment from the corneal limbs. Br.J. 0phthalmol. $2005 ; 89,1597-1600$.

26. Melles G.R.J., Lander F., Rietveld F.J.R., et al. A new surgical technique for deep stromal, anterior lamellar Keratoplasty.Br. J. 0phthalmol. 1999; 83, $327-333$.

27. Melles G.R.J., Remeijer L., Geerards A.J.M., et al. A quick surgical technique for deep, anterior lamellar Keratoplasty using viscodissection. Cornea $2000 ; 19,427-432$.

28. Anwar, M. Technique in lamellar Keratoplasty. Trans. Ophthalmol. Soc. UK 1974; 94, 163-171. 
29. Teichmann K.D. Lamellar Keratoplasty — a come back? Middle East J. Ophthalmol. 1999; 7, 59-60.

30. Patel S.V., Hodge D.0., Bourne W.M. Corneal endothelium and postoperative outcomes 15 years after penetrating Keratoplasty. Am.J. 0phthalmol. 2005; 139, 311319.

31. Wong T.Y., Chan C.M.L., Lim L., et al. Changing indications for penetrating Keratoplasty: a newly developed country's experience. Aust. NZ J. Ophthalmol. 1997; 25 , $145-150$

32. Durie D.S., Kezirian G.M. Femtosecond laser versusmechanical keratome flaps in wavefront-guided laser in situ keratomileusis. J. Cataract Refract. Surg. 2005; 31, $120-126$.

33. Durie D.S., Kezirian G.M. Femtosecond laser versusmechanical keratome flaps in wavefront guided laser in situ keratomileusis: prospective contralateral eye study. Cataract. Refract. Surg. 2005; 31, 120-126.

34. Tan D.T., Mehta J.S. Future directions in lamellar cornealtransplantation. Cornea 2007; 26 (9 Suppl. 1), 21-28.

35. Tillett CW. Posterior lamellar keratoplasty. Am J Ophthalmol. 1956; 41:530-3.

36. Barraquer J. Special methods in corneal surgery. In: King J.H, Mc Tigue J.W, editors. The cornea world congress. Washington, D.C: Rutterworths; 1965. pp. $586-604$.

37. Tillet C.W. Posterior lamellar keratoplasty. Am.J. Ophthalmol. 1956. V. 41. № 3. P. 530-533.

38. Barraquer J.I. Lamellar keratoplasty (special techniques). Ann. Ophthalmol. 1972. V. 4. P. 437-469.

39. Волков В.В., Дронов М.М. К разработке хирургического метода лечения эндотелиально-эпителиальной дистрофии роговицы // 1 съезд офтальмологов республик Закавказья. Сухуми, 1976.

40. Бойко А.В. Задняя частичная послойная кератопластика при посттравматических изменениях переднего отрезка: автореф. дис. канд. мед. наук. М., 1978. 20 с.

41. Гундорова Р.А., Бойко А.В. Пересадка задних слоев роговицы при посттравматическом врастании эпителия // Материалы 3 научной конференции офтальмологов Грузии. Тбилиси, 1974. С. 241-274.

42. Мамиконян В.Р., Труфанов С.В. Автоматизированная задняя послойная кератопластика в лечении буллезной кератопатии // Бюллетень СОРАМН. 2009. № 4. C. 37-39.

43. Busin M., Arffa R.C., Sebastiani A. Endokeratoplasty as an alternative to penetrating keratoplasty for the surgical treatment of diseased endothelium: initial results // Ophthalmology. 2000. V. 107. No11.P. 20770-2082.

44. Melles G.R.J., Egging F.A., Lander F. et al. A surgical technique for posterior lamellar keratoplasty // Cornea. 1998. V. 17.No 6.P. 618-626.

45. Melles G.R., Binder P.S., Anderson J.A. Variation in healing throughout the depth of long-term, unsutured, corneal wounds in human autopsy specimens and monkeys // Arch Ophthalmol. 1994. V. 112. No 1.P. 100-109.

46. Melles G.R., Binder P.S. Wound healing in sutured and unsutured corneal wound // Arch. Ophthalmol. 1990. V. 108. P.1460-1469.

47. Melles G.R., Lander F., Nieuwendaal C.P. The future of lamellar keratoplasty // Curr. Opin. Ophthalmol. 1999. V. 10. P. 253-259.

48. Melles G.R., Wijdb R.H., Nieuwendaal C.P. A technique to excise the Descemet's membrane from a recipient cornea (descemetorhexis) // Cornea. 2004. V. 23. P. 286-288.

49. Gorovoy M. Descemet stripping automated endothelial keratoplasty // Cornea. 2006. V. 25. No 8. P. 886-889.

50. Малюгин Б.Э., Мороз 3.И., Борзенок С.А., Дроздов И.В., Айба Э.Э., Паштаев А.Н. Первый опыт и клинические результаты задней автоматизированной послойной кератопластики (ЗАПК) с использованием предварительно выкроенных консервированных ультратонких роговичных трансплантатов // 0фтальмохирургия. 2013. № 3. С. 12-16.

51. Bursin M., Bhatt P.R., Scorcia V.A. Modified technique for Descemet membrane stripping automated endothelial keratoplasty to minimize endothelial cell loss // Arch. 0phtalmol.2008. V. 126. P. 1133-1137.

52. Melles G.R., Lander F., Rieveld F. Transplantation of Descemet's membrane carrying viable endothelium through a small scleral incision // Cornea. 2002 . V. 21 . No 4. P. 415-418.

53. Melles G.R., Ong T.S., Ververs B., van der Wees J. Descemet membrane endothelial keratoplasty (DMEK) //Cornea. 2006. V. 25. № 8. P. $987-990$.

54. Оганесян 0.Г., Гундорова Р.А., Воробьева М.А. Первый опыт трансплантации изолированной десцеметовой мембраны // Oftalmologijas Zurnals. 2008. No 9.P. $40-43$.

55. Seitz B., Langenbucber A., Hofmann-Rummelt C., Schlotzer-Schrebardt U., Naumann G.0. Non-mechanical posterior lamellar keratoplasty using the femtosecond laser (femto-PLAK) for corneal endothelial de-compensation // Am.J. Ophtalmol. 2003. V. 136. P. 769-772.

56. Cheng Y.Y., Pels E., Nuijts R.M. Femtosecond-laser-assisted Descemet's stripping endothelial keratoplasty // J. Cataract Refract. Surg. 2007. V. 33. P. $152-155$.

57. Dua H.S., Faraj L.A., Said D.G., Gray T., Lowe J. Human corneal anatomy redefined: A novel pre-Descemet's layer (Dua's layer) 0phthalmology. 2013; 120:1778-85.

58. Agarwal A., Dua H.S., Narang P., Kumar D.A., Agarwal A., Jacob S., et al. Pre-Descemet's endothelial keratoplasty (PDEK) Br J. Ophthalmol. 2014; 98:1181-5.

59. Dua H.S., Said D.G. Pre-Descemets endothelial keratoplasty: The PDEK clamp for successful PDEK. Eye (Lond) 2017; 31:1106-10.

60. В.П. Филатов. Круглый стебель в офтальмологии / М.: Медгиз, 1943.— 28 с.— (Восстановительная хирургия; вып. 2).

61. В.П. Филатов. Оптическая пересадка роговицы и тканевая терапия / М.: Медгиз, 1945. - 231 с., 6 л. ил.: ил.

62. В.П. Филатов. Возвращение зрения: Стенограмма публичной лекции, прочит. в Центр. лектории 0-ва в Москве / Всесоюз. 0-во по распространению полит. и науч. знаний. — Москва: [Правда], 1950 (тип. им. Сталина). — 39 с.: ил.

63. В.П. Филатов. Мои пути в науке / Одесса: Одес. обл. изд-во, 1955.- 160 с.

(c) Аксенова Светлана Владимировна ( aksenovamed@mail.ru ),

Васильева Ольга Александровна ( olga1 1vasilyeva@gmail.com ), Матяева Ангелина Дмитриевна ( matyaeva.lina@yandex.ru).

Журнал «Современная наука: актуальные проблемы теории и практики» 